\title{
Modeling and Simulation of a Renewable Energy Based-Medical Herb Dryer
}

\author{
Abdel-Shafy A. Nafeh, Emad Ahmed Sweelem, Faten Hosny Fahmy \\ PV Cells Department, Electronics Research Institute, Cairo, Egypt. \\ Email: abdelshafyn@yahoo.com, emadsweelem@yahoo.com, fatenhf@yahoo.com
}

Received December $3^{\text {rd }}, 2012$; revised January $14^{\text {th }}, 2013$; accepted January $21^{\text {st }}, 2013$

Copyright (C) 2013 Abdel-Shafy A. Nafeh et al. This is an open access article distributed under the Creative Commons Attribution License, which permits unrestricted use, distribution, and reproduction in any medium, provided the original work is properly cited.

\begin{abstract}
The medical herbs should be dried directly after harvesting, otherwise, insects and fungi spoilage them. Conventional drying methods such as open sun drying and conventional fuel dryers are not suitable, since they contaminate the herbs, decrease the drying efficiency and at the same time increase the drying cost. Therefore, the recent trend is toward the harnessing the renewable energy to dry the medical herbs. This paper presents a new controlled drying system, which uses a solar collector and an electric heater to heat the drying air, and a PV-WIND hybrid system to supply the required electric energy to the dryer electric load. This paper also presents the dynamic modeling, simulation, and control of the suggested thermal system (i.e., the solar thermal system and the electrical heater). Moreover, this paper, exhibits the different results of the thermal system, to check the effectiveness of this system that fulfills the requirements of the drying operation. The system results are found to satisfy the ultimate goals of the drying operation.
\end{abstract}

Keywords: Medical Herb Dryer; Solar Thermal System; Renewable Energy; Dynamic Modeling

\section{Introduction}

In most countries, enormous of food losses have resulted from spillage, contamination, attack by inserts/rodents/ birds and deterioration during the storage period. There is a number of factors, which are responsible for the post harvest losses, such as system of harvesting, processing, storage, handling, and marketing. Drying of product is one of the important post harvest processes and it has enough potential to reduce the post harvest losses, and to prevent spoilage of the product in storage drastically. Moreover, good drying technique can enhance the quality of the product significantly [1]. Therefore, the drying of medical herbs must be accomplished as soon as possible after harvesting, to increase the quality of the herb and to prevent the expected contamination and losses caused by infestation of rodents, birds, insects, and fungi which thrive in moist conditions [1,2].

Traditional open sun drying, where the product to be dried is exposed directly to the sun, has many disadvantages such as degradation by wind-blown debris, rain, insect infestation, human and animal interference which will result in contamination of the product. Also, it extends the drying time significantly. High-speed dryers, on the other hand, use high-cost conventional energy sources for their operation. Moreover, they may not be reliable and environmentally safe. Instead these dryers may be operated by using the renewable energy sources, such as photovoltaic (PV) modules, solar collectors and wind turbines etc.

In this paper a new controlled herb dryer system is developed. This dryer uses a flat plate solar collector to heat the drying air, and a PV-WIND hybrid system to feed the electrical energy to the dryer electric load.

\section{The Suggested Herb Drying System}

The configuration of the suggested medicinal herb dryer system is shown in Figure 1. The diagram consists of three main systems: the solar thermal system, the dryer, and the renewable energy system. The main function of the solar thermal system is to supply the inlet air to the dryer with the required solar thermal energy that is suitable to accomplish the drying process. While, that of the renewable energy system is to feed the electrical load of the dryer with the required electrical energy, to ensure good and continuous drying operation [3].

\section{Modeling of the Thermal System}

In this section, the energy balance principle is utilized to develop the complete dynamic modeling of the compo- 


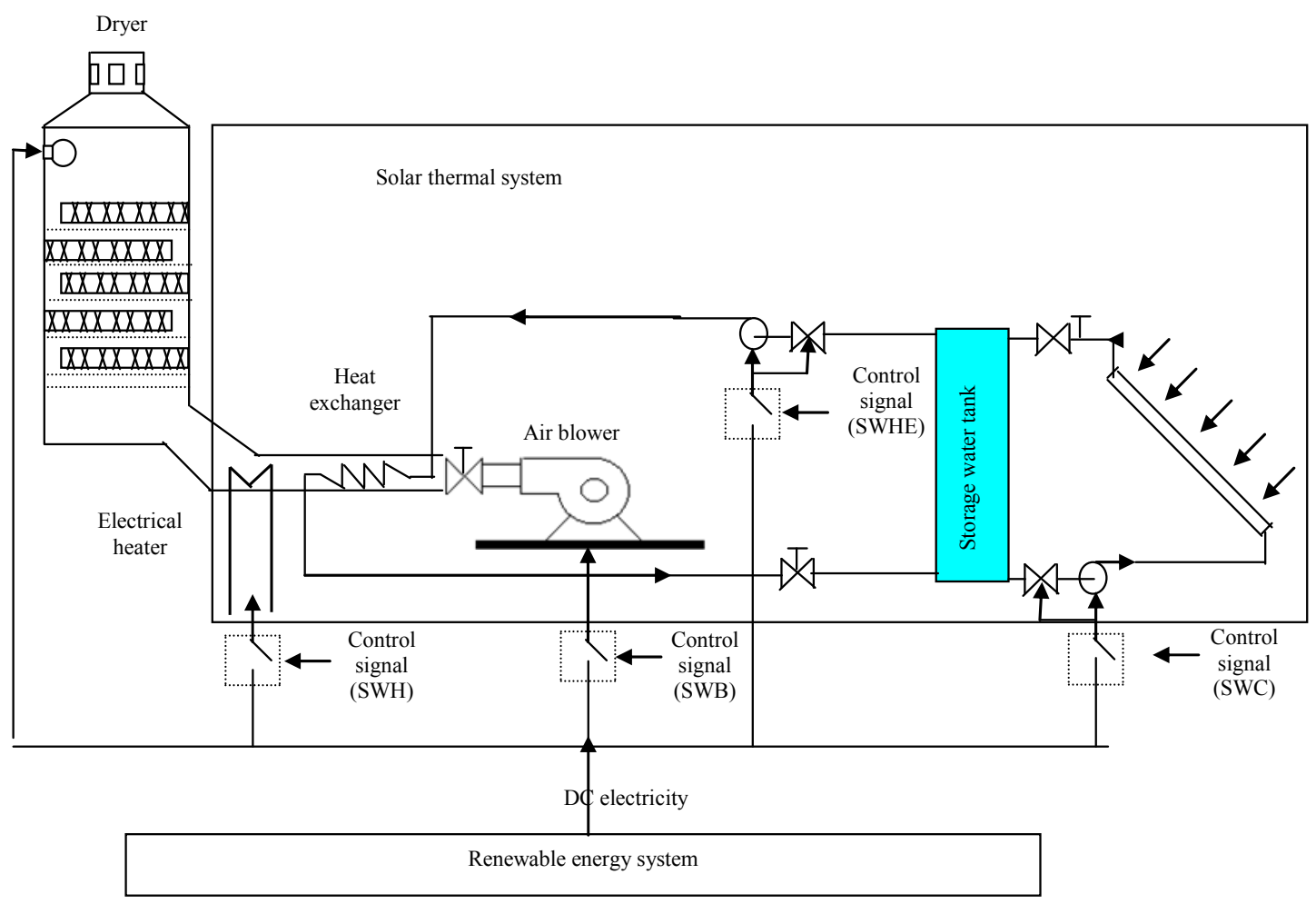

Figure 1. The medical herb dryer system.

nents of the suggested solar thermal system and that of the electrical heater.

\subsection{Modeling of the Solar Collector}

A flat plate solar collector type is used, to absorb the solar energy from the sun and transfers it into the water that flows inside its parallel tubes, which are attached to a black metal plate. This type of collectors works on both the direct and diffuse components of the solar radiation. Therefore, it stills function when the direct component is cut off by the effect of clouds $[4,5]$.

The water in the collector will absorb the solar energy with the rate

$$
\dot{Q}_{a b s}=(\tau \alpha)_{e f f} A_{c} \operatorname{Rad}
$$

and at the same time will loss a certain amount of heat energy to the environment, $\dot{Q}_{a m b}$, given by

$$
\dot{Q}_{\text {amb }}=\bar{U}_{c} A_{c}\left(T_{\text {cout }}-T_{\text {air }}\right)
$$

where

$\tau$ transmissivity of the collector (fraction of incident energy transmitted);

$\alpha$ absorbitivity of the collector (fraction of insolation);

$(\tau \alpha)_{\text {eff }}$ effective absorbance of collector's cover $(=0.8)$;

$A_{c}$ collector's area $\left(=2 \mathrm{~m}^{2}\right)$;

Rad solar illumination

$\bar{U}_{c}$ overall thermal loss coefficient $\left(=8.38 \mathrm{~W} / \mathrm{m}^{2}{ }^{\circ} \mathrm{C}\right)$;

$T_{\text {cout }}$ water temperature at the collector outlet;
$T_{\text {air }}$ ambient temperature.

Thus, an energy balance $[2,4]$ on the collector (Figure 2) will lead to the following differential equation

$$
\frac{\mathrm{d} T_{\text {cout }}}{\mathrm{d} t}=-\frac{\dot{m}_{c w}}{\rho_{w} V_{c w}}\left(T_{\text {cout }}-T_{c i n}\right)+\frac{\dot{Q}_{a b s}-\dot{Q}_{a m b}}{\rho_{w} V_{c w} C_{p w}}
$$

where $T_{\text {cin }}$ water temperature at the collector inlet;

$\dot{m}_{c w}$ mass flow rate of water in the collector;

$C_{p w}$ specific heat of water;

$\rho_{w}$ density of water;

$V_{c w}$ volume of water in the collector.

\subsection{Modeling of the Storage Tank}

Due to the stratified nature of the storage water tanks, the used tank is considered to be composed of five identical layers, as shown in Figure 3. The top layer (i.e., layer \#1) is the highest temperature layer, while the bottom layer (i.e., layer \#5) is the lowest temperature layer. The outlet water from the collector enters the tank at the top layer

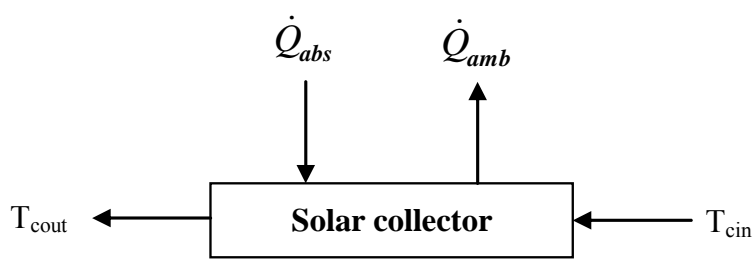

Figure 2. Energy balance on the collector. 


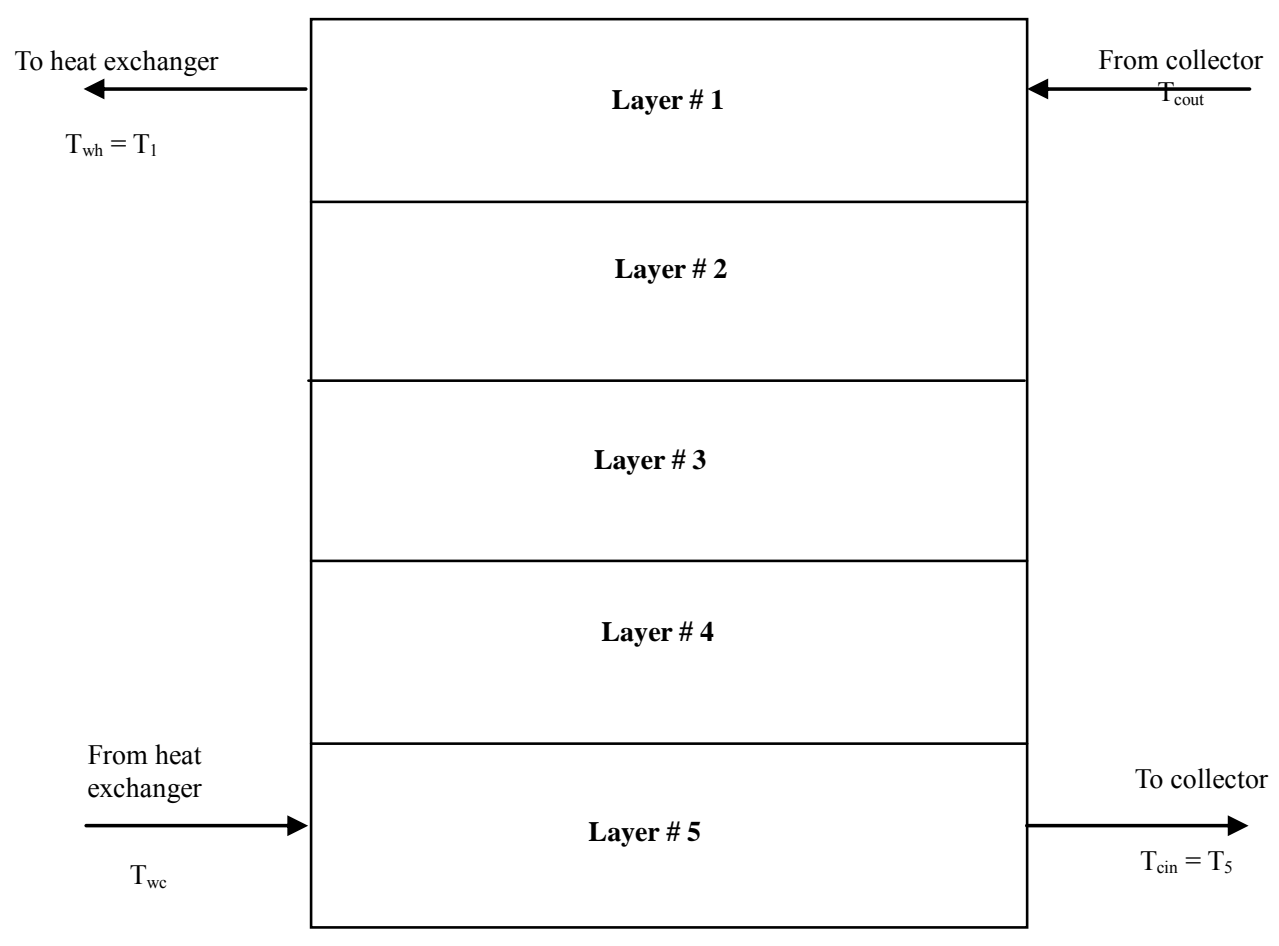

Figure 3. Stratified water storage tank.

with a temperature $T_{\text {cout, }}$, and the water leaves the tank to the collector from the bottom layer (i.e., the water temperature at the collector inlet $T_{\text {cin }}$ is nearly the same as that of the bottom layer $T_{5}$ ). At the same time, the water outputs from the top layer of the tank at a temperature $T_{w h}=T_{1}$, to feed the heat exchanger side. Also, the water returns from the load side to the bottom layer of the tank with temperature $T_{w c}$.

Generally, the circulation of water in the collector side increases the thermal energy of the tank, while the circulation of water in the load side may increase or decrease the stored energy of the tank. Therefore, an energy balance $[2,3]$ on a general layer $(m)$ of the tank (Figure 4) yields

$$
\frac{\mathrm{d} T_{m}}{\mathrm{~d} t}=\frac{\dot{Q}_{c m}}{m_{m} C_{p w}}+\frac{\dot{Q}_{H E m}}{m_{m} C_{p w}}-\frac{\dot{Q}_{\text {Loss }}}{m_{m} C_{p w}}
$$

where

$$
\begin{gathered}
\dot{Q}_{c m}=\left\{\begin{array}{lc}
\dot{m}_{c w} C_{p w}\left(T_{m-1}-T_{m}\right), & T_{\text {cout }}>T_{1} \\
\dot{m}_{c w} C_{p w}\left(T_{\text {cout }}-T_{m}\right), & T_{m-1}>T_{\text {cout }}>T_{m}
\end{array}\right. \\
\dot{Q}_{\text {HEm }}=\left\{\begin{array}{lc}
\dot{m}_{E H w} C_{p w}\left(T_{m+1}-T_{m}\right), & T_{w c}<T_{5} \\
\dot{m}_{H E w} C_{p w}\left(T_{w c}-T_{m}\right), & T_{m+1}<T_{w c}<T_{m}
\end{array}\right.
\end{gathered}
$$

and

$$
\dot{Q}_{\text {Loss }}=\bar{U}_{s t} A_{m}\left(T_{m}-T_{\text {air }}\right)
$$

The symbols of Equation (4) are defined as $T_{m}$ temperature of layer $m(m=1,2, \cdots, 5)$;

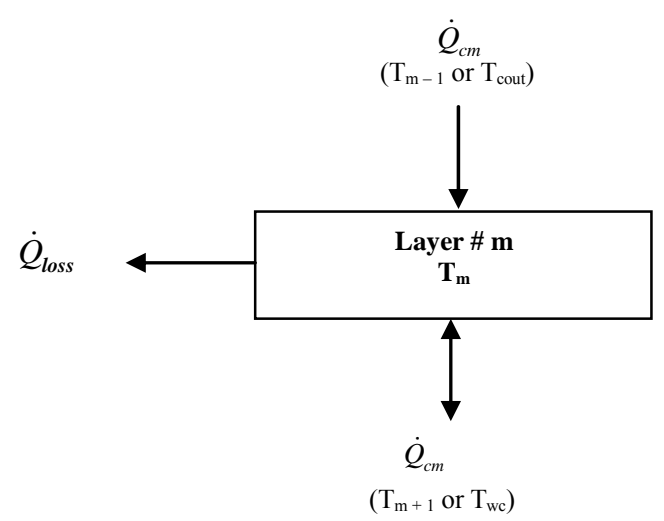

Figure 4. Energy balance on layer \#m.

$T_{w c}$ outlet temperature of water from the heat exchanger side;

$m_{m}$ mass of water in layer $m$;

$\dot{m}_{\text {HEw }}$ mass flow rate of water in the heat exchanger side;

$A_{m}$ surface area of layer $m$;

$\bar{U}_{s t}$ overall loss coefficient for the exposed storage surface $\left(=10.08 \mathrm{~W} / \mathrm{m}^{2}{ }^{\circ} \mathrm{C}\right)$.

\subsection{Modeling of the Heat Exchanger}

The used heat exchanger is parallel flow water to air type, which consists of two concentric pipes as shown in Figure 5(a). The hot fluid (i.e., the water) passes inside the smaller diameter pipe, while the cold fluid (the air) passes through the space between the two pipes. It is 


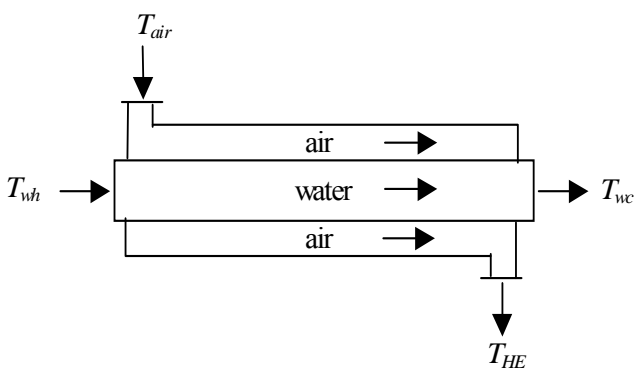

(a)

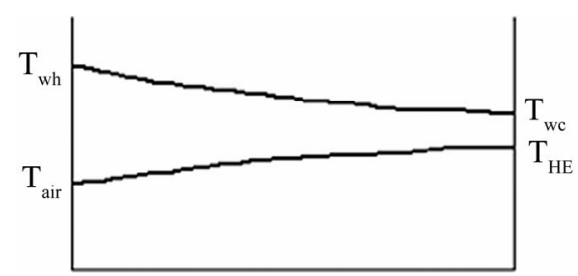

(b)

Figure 5. Parallel-flow heat exchanger: (a) Schematic diagram; (b) Temperature distribution along tube axis.

necessary to note here that the two fluids are co-flow. Where, during the co-flow of the two fluids along the heat exchanger length, the hot fluid transfers heat through the shell of the smaller diameter pipe to the cold fluid. Therefore, a temperature drop will occur in the hot fluid continuously and at the same time a temperature rise will occur in the cold fluid along the length of the heat exchanger (Figure 5(b)). Where, the hot water and the ambient air enter the heat exchanger with temperatures $T_{w h}$ and $T_{\text {air }}$, respectively; whereas their outlet tempe- ratures are $T_{w c}$ and $T_{H E}$, respectively.

Knowing the heat exchanger efficiency $\eta_{H E}$, the rate of transferring the heat energy from the water to the air

$Q_{w-a}$, will be

$$
\dot{Q}_{w-a}=\dot{m}_{H E w} C_{p w}\left(T_{w h}-T_{w c}\right) \eta_{H E}
$$

Therefore, applying the energy balance equation $[2,4]$ on the heat exchanger (Figure 6) will lead to the differential equation

$$
\frac{\mathrm{d} T_{H E}}{\mathrm{~d} t}=-\frac{\dot{m}_{\text {air }}}{\rho_{\text {air }} V_{H E}}\left(T_{H E}-T_{\text {air }}\right)+\frac{\dot{Q}_{w-a}}{\rho_{\text {air }} V_{H E} C_{\text {pair }}}
$$

where $\dot{m}_{\text {air }}$ mass flow rate of the air;

$\rho_{\text {air }}$ density of the air;

$V_{H E}$ volume of the heat exchanger;

$C_{\text {pair }}$ specific heat of the air.

The relation between the inlet and outlet temperatures of the heat exchanger, can be outlined using the heat exchanger effectiveness $\varepsilon_{H E}$, as [6]

$$
\varepsilon_{H E}= \begin{cases}\frac{T_{H E}-T_{a i r}}{T_{w h}-T_{a i r}}, & \dot{m}_{H E w} C_{p w}>\dot{m}_{a i r} C_{p a i r} \\ \frac{T_{w h}-T_{w c}}{T_{w h}-T_{a i r}}, & \dot{m}_{H E w} C_{p w}<\dot{m}_{a i r} C_{p a i r}\end{cases}
$$

\subsection{Modeling of the Electrical Heater}

The main function of the electrical heater is to make the auxiliary heating of drying air. The auxiliary heating means that the electrical heater will operate only if the temperature of the output air $T_{H E}$ from the heat exchanger is lower than the required value to adjust the air drying temperature $T_{\text {dryer }}$ at $40^{\circ} \mathrm{C}$.

If the rated power of the electrical heater is $P_{\text {heater }}$ and the heater efficiency is $\eta_{\text {heater }}$, then the rate of heat added to the drying air (in the electrical heating chamber) [7] will be

$$
\dot{Q}_{\text {heater }}=P_{\text {heater }} \times \eta_{\text {heater }}
$$

Thus, by applying the energy balance principle on the electrical heating chamber (Figure 7) will yield [8]

$$
\frac{\mathrm{d} T_{\text {dryer }}}{\mathrm{d} t}=-\frac{\dot{m}_{\text {air }}}{\rho_{\text {air }} V_{H C}}\left(T_{\text {dryer }}-T_{H E}\right)+\frac{\dot{Q}_{\text {heater }}}{\rho_{\text {air }} V_{H C} C_{\text {pair }}}
$$

where $V_{H C}$ volume of the heating chamber of the electrical heater.

\section{Control of the Thermal System Including the Air Blower}

The control system of the thermal system including the air blower performs control and protection functions for the components of the thermal system and the air blower in the dryer system of Figure 1. Where, it optimizes the operation of the following electrical loads:

1) The air blower;

2) The water circulation valve and pump of the collector side;

3) The water circulation valve and pump of the heat exchanger side;

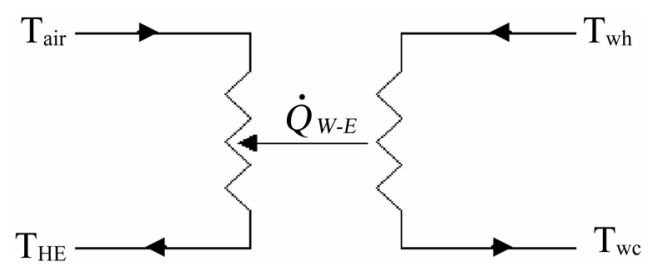

Figure 6. Energy balance on the heat exchanger.

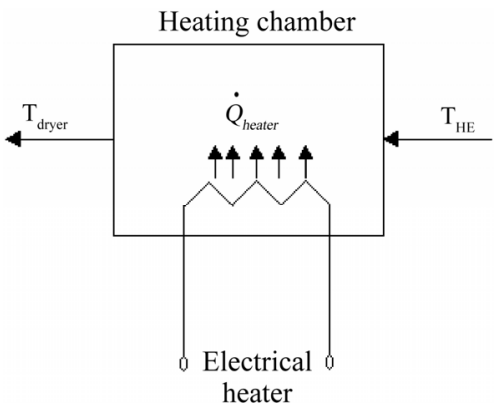

Figure 7. Energy balance on the electrical heating chamber. 
4) The electrical heater.

Therefore, there will be four control signals in the system (Table 1). The first three control signals are switched control signals based on logic control decision and the fourth is a switched control signal based on/off controller (or thermostat).

Where, $T_{\text {ref }}$ is the desired drying temperature of the air and SWB is the switching control signal of the air blower, SWC is the switching control signal of the valve and pump in the collector side, SWHE is the switching control signal of the valve and pump in the heat exchanger side.

\section{Simulation of the Thermal System}

In this simulation the mathematical models of the differ- ent components of both the solar thermal system and the electrical heater are used to simulate the complete suggested thermal system, by using the MATLAB-SIMULINK. Figure 8 shows the designed SIMULINK model of the dryer thermal system. Each component, in the simulation model, has its own parameters and input and output variables.

\section{Simulation Results of the Thermal System}

The performance of the complete components in both the solar thermal system and the electrical heater with the corresponding control signals are necessary to evaluate the control capability of the proposed system. The performance of the system is preferably evaluated by compar-

Table 1. Thermal system control.

\begin{tabular}{lcc}
\hline \multicolumn{1}{c}{ Component } & Control signal & Control rule \\
\hline Air blower & SWB & If $\left(T_{\text {ref }} \neq 0\right)$ then (SWB will be on and vice versa) \\
Valve and pump in collector side & SWC & If $\left((\right.$ Rad $\left.>0) \&\left(T_{\text {cout }}>T_{\text {cin }}\right)\right)$ then (SWC will be on and vice versa) \\
Valve and pump in HE side & SWHE & If $\left(T_{\text {air }}<T_{\text {ref }}\right)$ then (SWHE will be on and vice versa) \\
Electrical heater & SWheater & On/off control (thermostat)
\end{tabular}

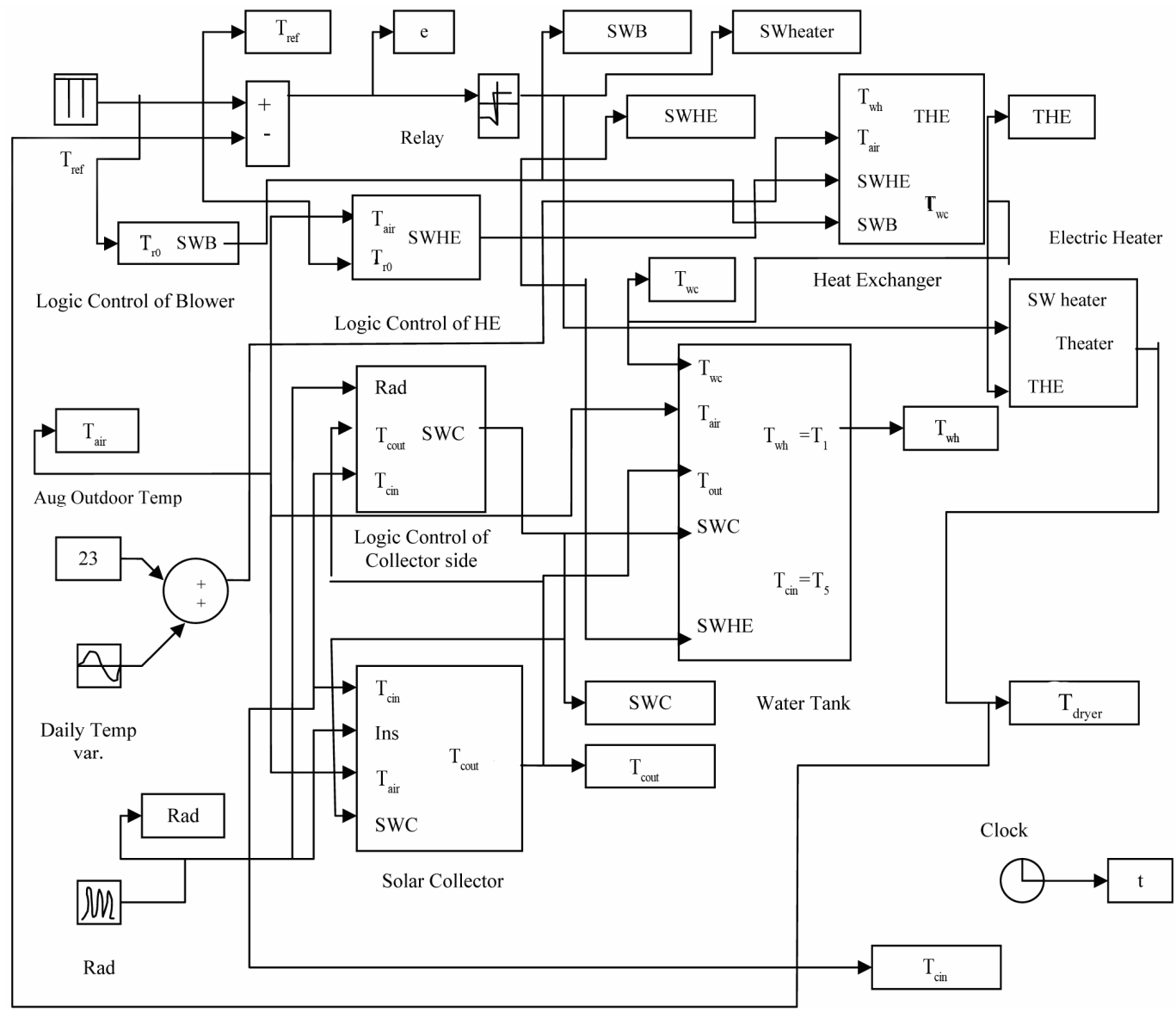

Figure 8. SIMULINK model of the thermal system. 
ing the performance of the system in a summer day with that of a winter day.

The meteorological data in this work are obtained at two different days with different atmospheric conditions. Figures 9(a) and (b) show the variations of the solar insulation incident on the surface of the solar collector on summer and winter days, respectively (in Sinai Peninsula (Abu Rudies) [9]). While, Figure 10 shows variation of the corresponding ambient temperature.

The performance of the solar collector during the summer and winter days is shown in Figures 11 and 12, respectively. Figure 11, as shown, includes the switching control signal of the collector-side path, while Figure 12 shows the temperatures of the water at the inlet and outlet sides of the collector. It is shown from Figures $\mathbf{1 1}$ and 12 that the used collector is able to heat the water that flows through it, whenever there is solar illumination;

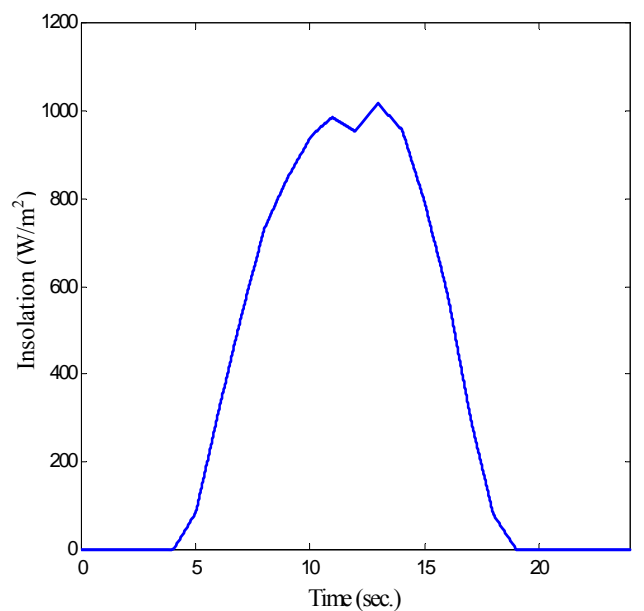

(a)

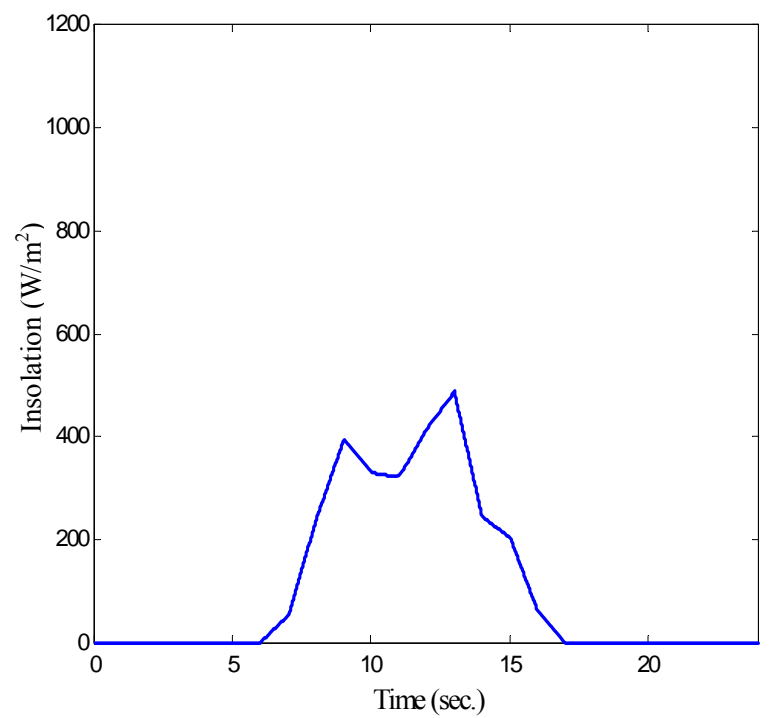

(b)

Figure 9. Variation of solar insolation: (a) Insolation of the summer day; (b) Insolation of the winter day.

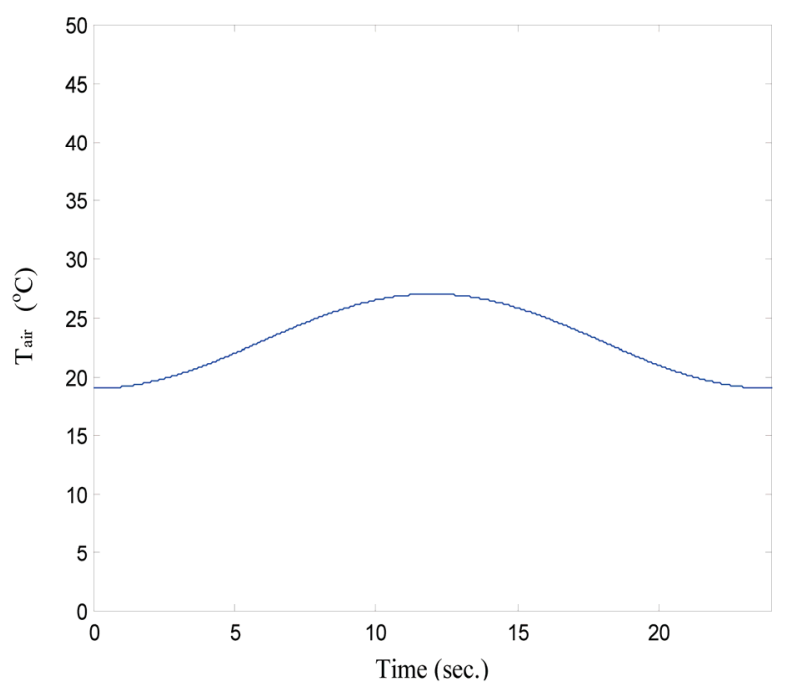

Figure 10. Variation of ambient temperature.

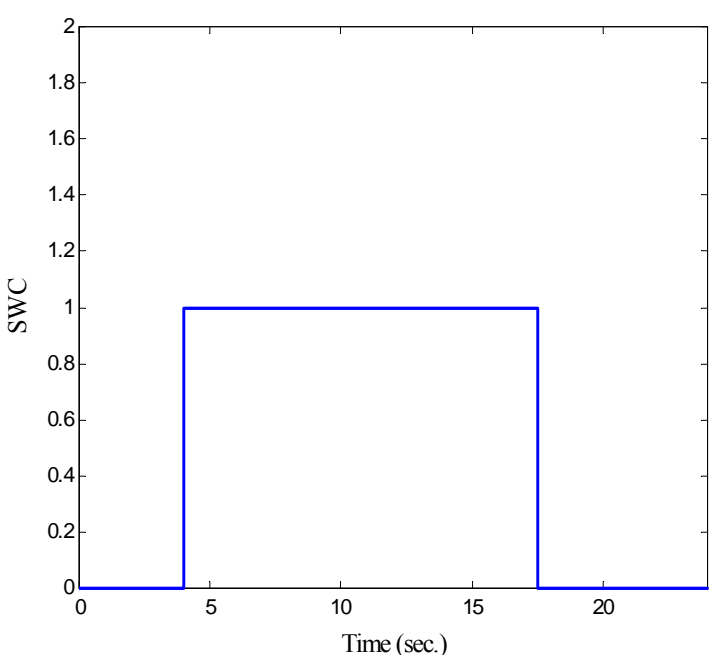

(a)

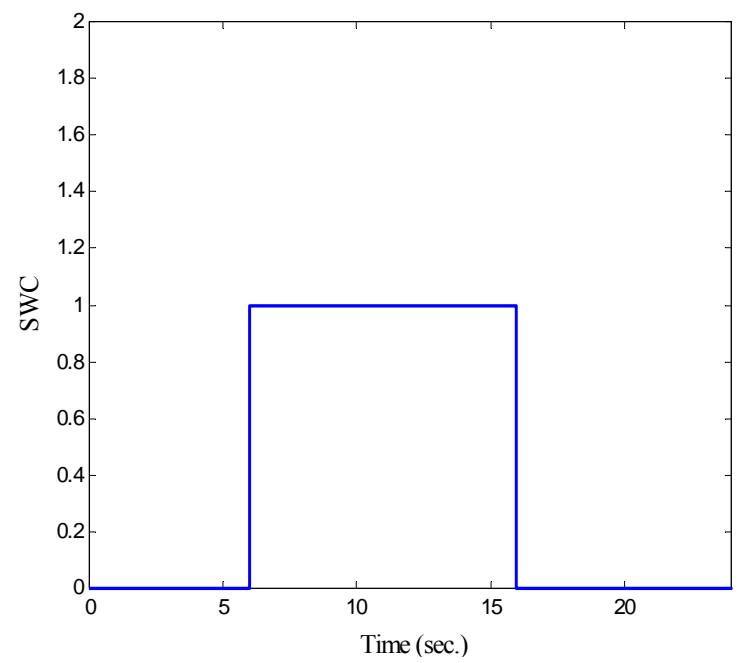

(b)

Figure 11. Switching signal of the collector side: (a) During summer day; (b) During winter day. 


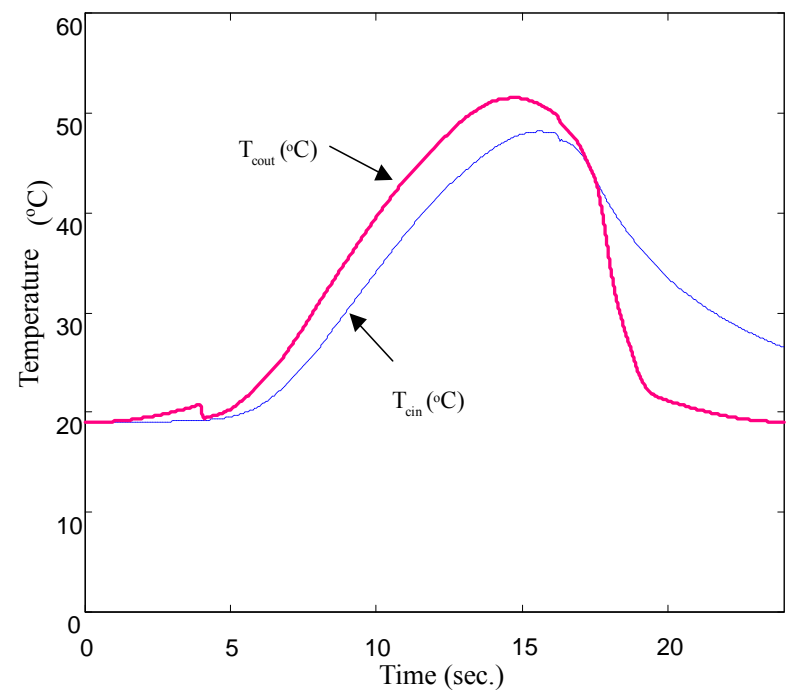

(a)

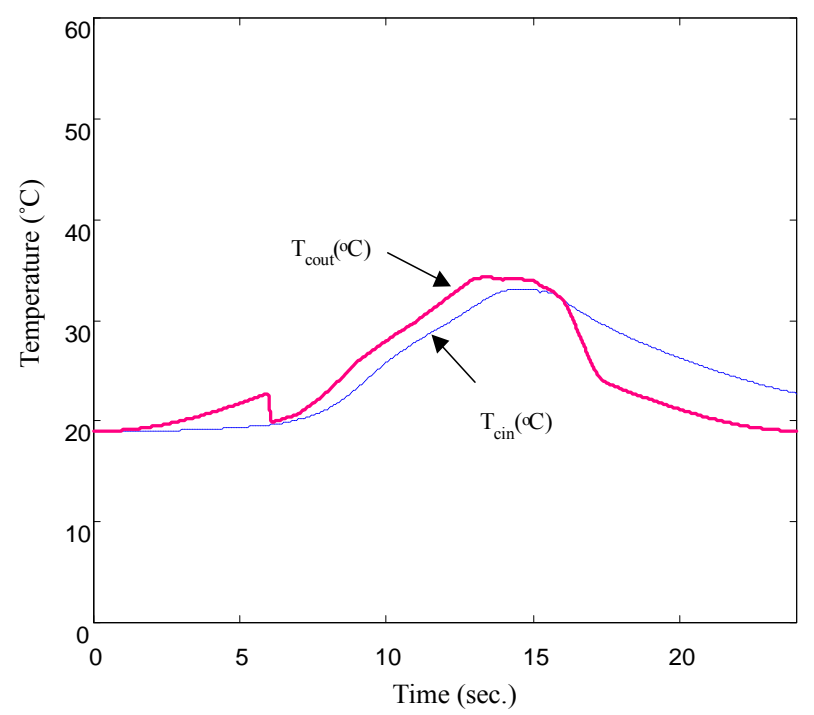

(b)

Figure 12. Inlet and outlet temperatures of the collector: (a) During summer day; (b) During winter day.

where the heating of the water is proportional to the incident insolation level. Also, it is cleared that the water continues to flow in the collector as long as the temperature of the water at the collector outlet is greater than that at the collector inlet. The initial apparent-rise of the outlet temperature compared with the inlet one, for the two cases, is due to: using the same value of the initial conditions for the two temperatures, the water does not flow in the collector during the night period, and the corresponding variation in the ambient temperature.

Figures 13(a) and (b) show the performance of the storage water tank during the summer and winter days, respectively. Thus, the effect of stratification on the tank is shown in this figure, where the bottom layer exhibits the lowest temperature and the top layer exhibits the

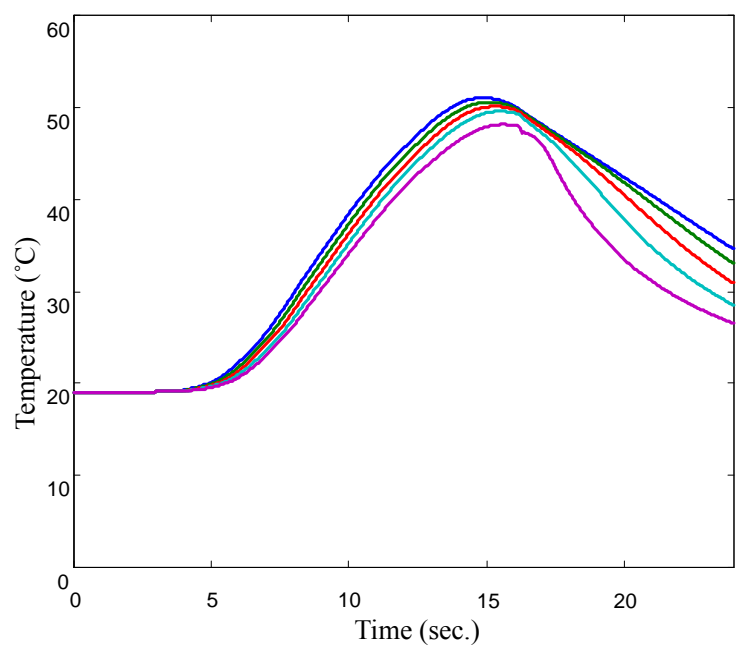

(a)

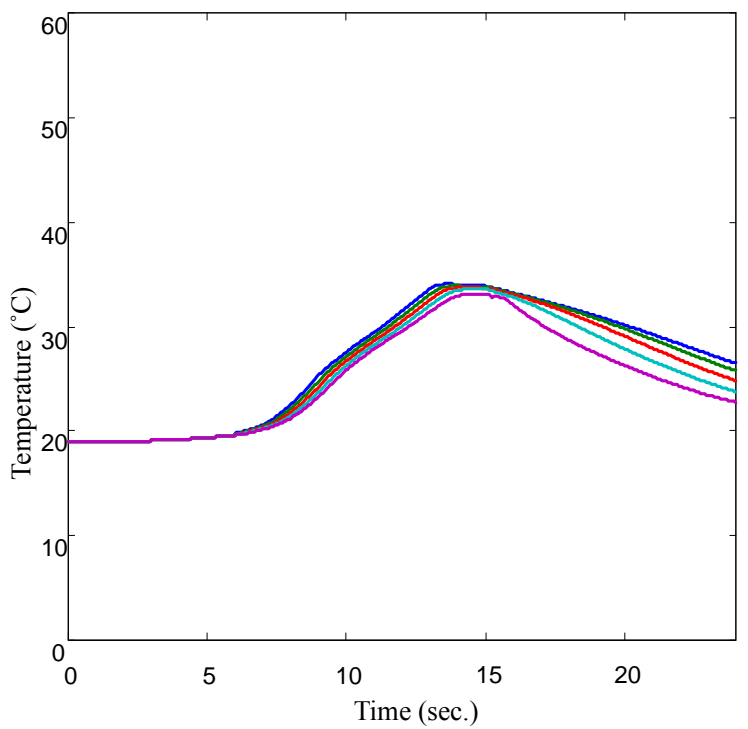

(b)

Figure 13. Temperature of the tank layers: (a) During summer day; (b) During winter day.

highest temperature of all the tank layers. It is indicated that the temperatures of the tank layers increase during the daylight hours and decrease during the night hours, such that the variation of the temperatures is proportional to the variation in the solar insolation.

The performance of the heat exchanger during the summer and winter days is shown in Figures 14-17, respectively. Figures 14 and 15 include the switching control signals of the air blower and the heat exchanger side, respectively. While the performance of the inlet and outlet temperatures of the heat exchanger water and the performance of the inlet and outlet temperatures of the heat exchanger air are shown in Figures 16 and 17, respectively. Thus, it is clear from these figures that the switching control signal of the air blower exists as long as there are herbs in the dryer, and that of the heat exchanger 


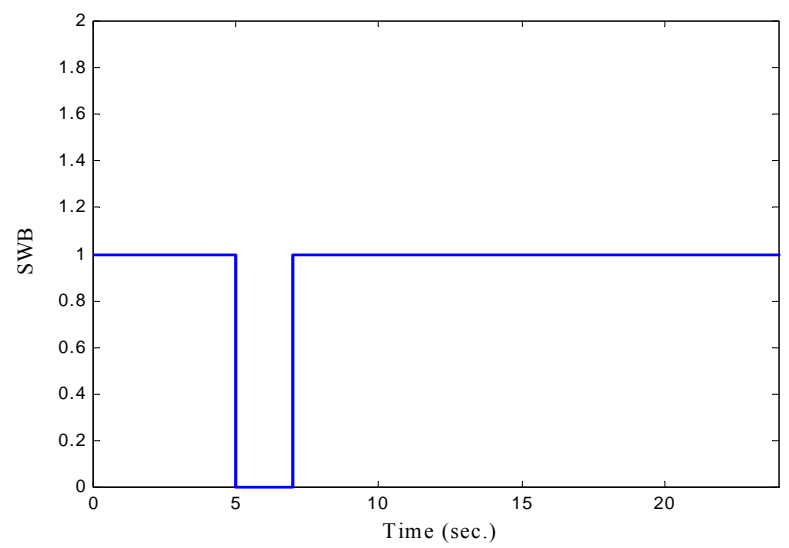

(a)

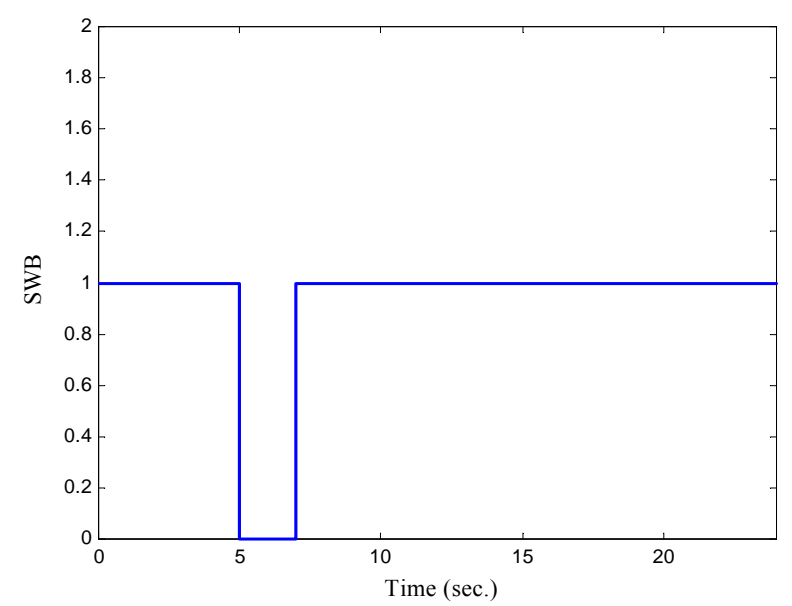

(b)

Figure 14. Switching signal of the air blower: (a) During summer day; (b) During winter day.

side exists as long as the ambient temperature is lower than the desired drying temperature $T_{\text {ref }}$. Also, the inlet temperature of the heat-exchanger water is the temperature of the tank top layer (Figure 13) and the shown difference in temperature between the inlet and the outlet water (which depends on the solar insolation incident on the collector) expresses the rate of the thermal energy transferred to the heat exchanger air. Moreover, the outlet temperature of the heat-exchanger air is increased with respect to the ambient temperature according to the quantity of heat transferred from the water.

\section{Conclusion}

This paper suggests and develops a new controlled drying system for the medical herbs. The suggested drying system includes the following three systems: the solar thermal system, the dryer, and the renewable energy system. The main function of the solar thermal system is to supply the dryer inlet air with the required thermal energy through utilizing the flat plate solar collector. While, that of the renewable energy system, which comprises

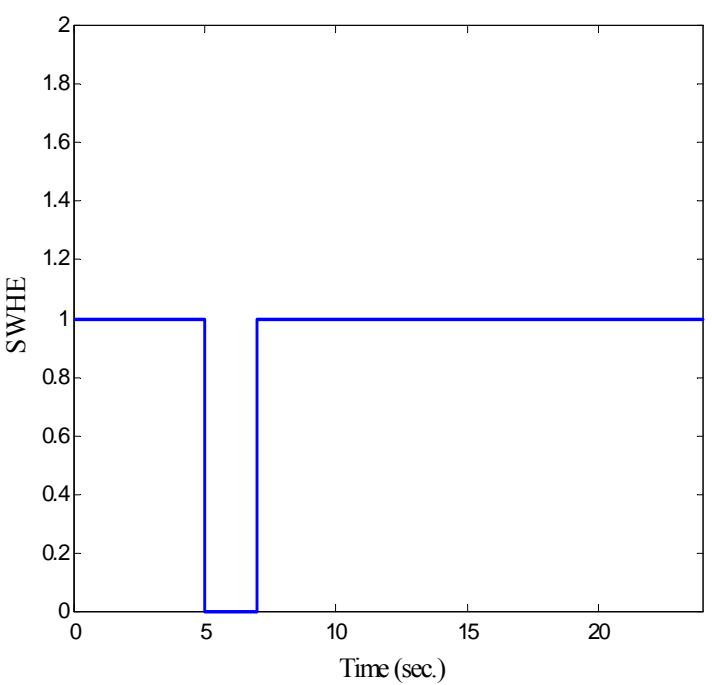

(a)

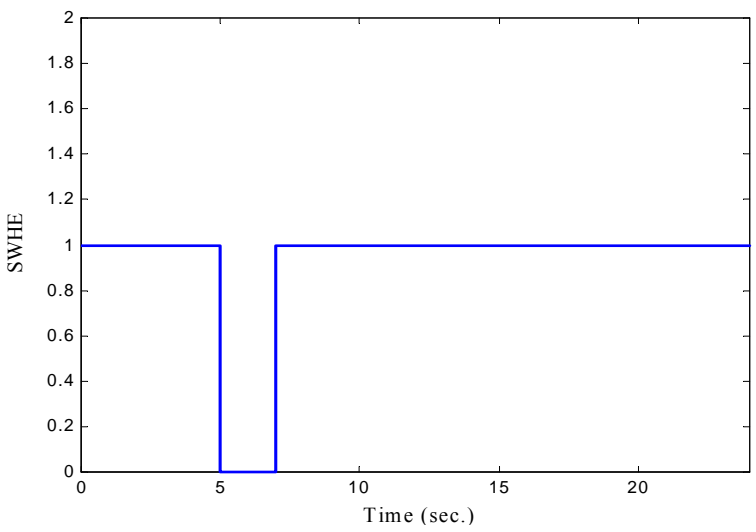

(b)

Figure 15. Switching signal of the heat exchanger side: (a) During summer day; (b) During winter day.

hybrid photovoltaic and wind energy sources, is to feed the electrical load of the dryer with the required electrical energy. This paper presents, also, the dynamic modeling and simulation of the suggested drying system. The system results are indicated that the used collector is able to heat the water that flows through it, whenever there is solar illumination; where the heating of the water is found to be proportional to the incident insolation level. Also, the water flows in the collector as long as the temperature of the water at the collector outlet is greater than that at the collector inlet and there is illumination. The temperatures of the layers of the storage water tank increase during the daylight hours and decrease during the night hours; such that the variation of the temperatures is proportional to the variation in the solar insolation. The air blower operates as long as there are herbs in the dryer, and the water flows in the heat exchanger as long as the ambient temperature is lower than the desired drying temperature. Also, the drop in water temperature between the inlet and the outlet sides of the heat exchanger is used 


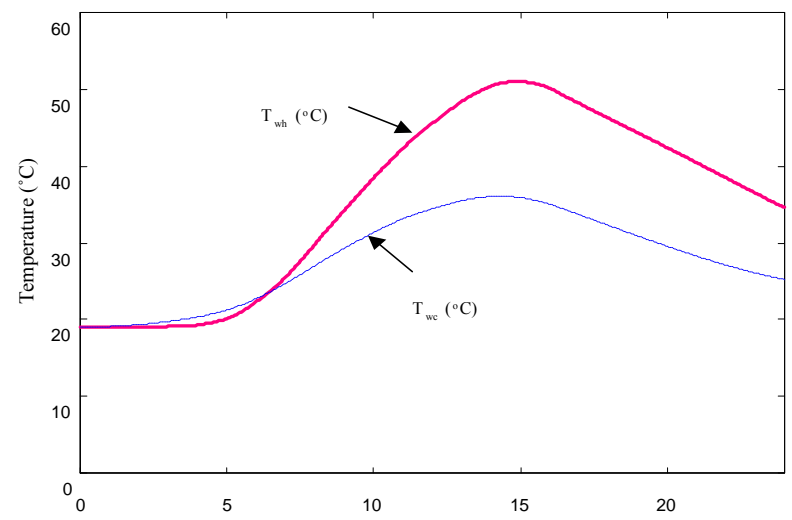

(a)

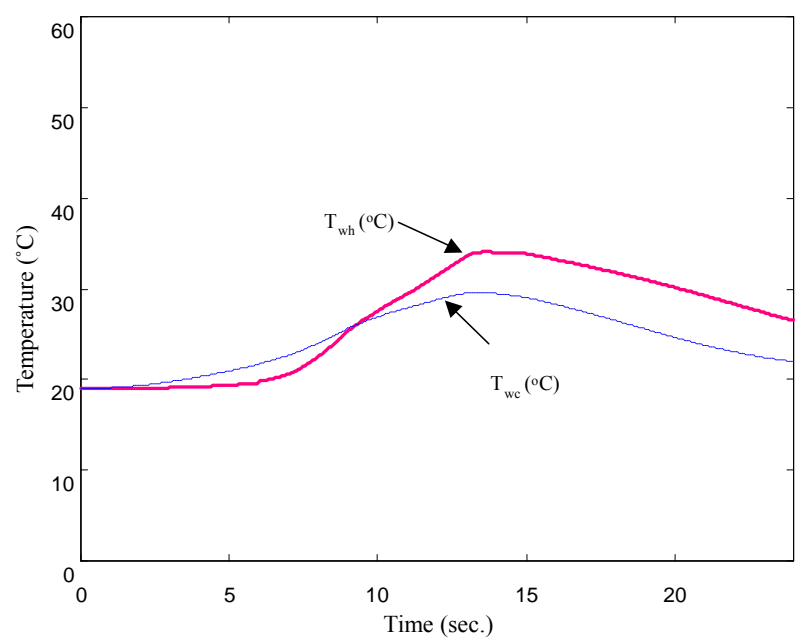

(b)

Figure 16. Inlet and outlet temperature of the heat exchanger water: (a) During summer day; (b) During winter day.

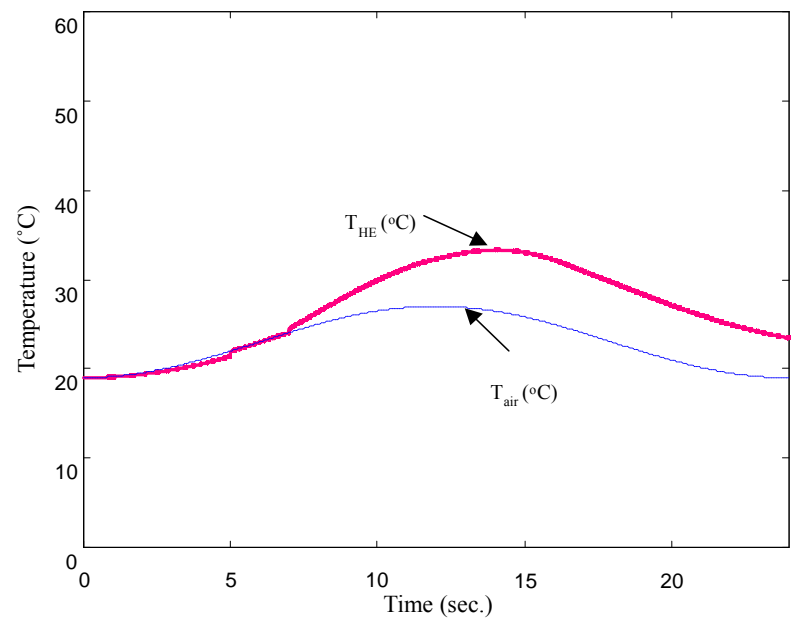

(a)

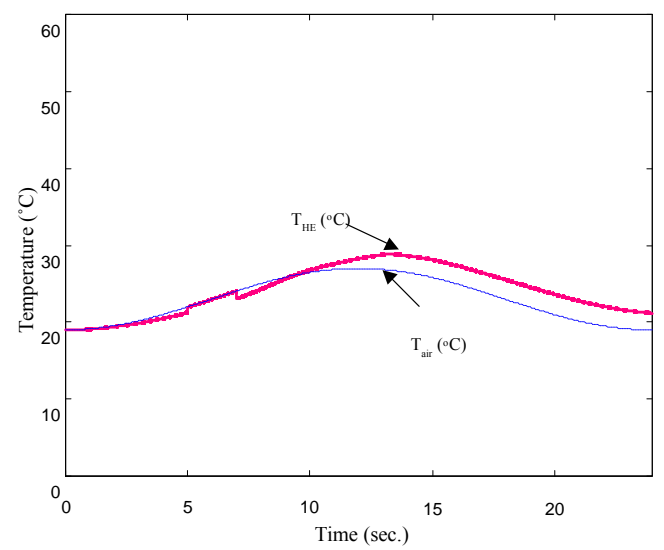

(b)

Figure 17. Inlet and outlet temperature of the heat exchanger air: (a) During summer day; (b) During winter day.

to rise the temperature of the outlet air from heat exchanger.

\section{REFERENCES}

[1] G. Grang and H. P. Kumar, "Developments in Solar Drying," Proceedings of the Second Asian-Oceania Drying Conference (ADC 2001), Pulau Pinang, 2001, pp. $297-$ 319.

[2] J. Howell, R. Bannerot and G. Vliet, "Solar-Thermal Energy Systems: Analysis and Design," McGraw-Hill, Inc., New York, 1982.

[3] A. Vieira da Rosa, "Fundamentals of Renewable Energy Processes," 3rd Edition, Academic Press, Waltham, 2013.

[4] J. W. Twidel and A. D. Weir, "Renewable Energy Resources," Cambridge, London, 1986. doi: 10.4324/9780203478721

[5] X. Xu, M. M. Meyers, B. G. Sammakiak and B. T. Murray, "Thermal Modeling and Life Prediction of Water-Cooled Hybrid Concentrating Photovoltaic/Thermal Collectors," Journal of Solar Energy Engineering, Transactions of the ASME, Vol. 135, No. 1, 2013.

[6] T. A. Stuetzle, "Automatic Control of the 30 MWe SEG VI Parabolic Trough Plant," M.Sc. Thesis, WisconsinMadison University, Madison, 2002.

[7] T. A. Stuetzle, "Automatic Control of the 30 MWe SEG VI Parabolic Trough Plant," M.Sc. Thesis, WisconsinMadison University, Madison, 2002.

[8] P. M. Doran, "Bioprocess Engineering Principles," 2nd Edition, Academic Press, Waltham, 2013.

[9] N. Elshahat and A. Zeit, "Aromatic Plants \& Its Agricultural-Medical Products,” Arabic, Inc., Egypt, 2003. 